Revista Científica de FAREM-Estelí

Medio ambiente, tecnologia y desarrollo humano

Año 10 | Núm. 39| Julio-septiembre, 2021

ISSN: 2305-5790

https://rcientificaesteli.unan.edu.ni

DOI: https://doi.org/10.5377/farem.v10i39.12617

\section{Factores geográficos en la evolución urbana de la zona central histórica de la ciudad de Tipitapa, Nicaragua I946-2020}

\section{Geographical factors in the urban evolution of the historical central area of the city of Tipitapa, Nicaragua 1946-2020}

\section{Samanta María Espinoza Rivera}

Universidad Nacional Autónoma de Nicaragua, Managua

https://orcid.org/0000-0003-0994-5185

samanta.espinoza@unan.edu.ni

\section{María Dolores Álvarez Arzate}

Universidad Nacional Autónoma de Nicaragua, Managua

https://orcid.org/0000-0002-6836-1318

malvarez@unan.edu.ni

\section{RESUMEN}

El presente artículo, parte de la tesis doctoral de la autora, donde se logró identificar los factores geográficos que influyeron en la evolución urbana de la zona central histórica de la ciudad de Tipitapa en los años 1946, 1969, 1996, 2000, 2018 y 2020. Desde el enfoque del análisis geográfico, auxiliado de los Sistema de Información Geográfica se profundiza en la descripción de los usos de suelo, la morfología urbana, así como los elementos naturales y culturales más representativos de la estructura urbana, componentes del paisaje urbano. Tipo de investigación cualitativa. Los principales resultados muestran que los factores geográficos que influyeron en el desarrollo de la zona central histórica de la ciudad de Tipitapa, se destaca la ubicación geográfica estratégica con relación a las regiones del norte y pacífico de Nicaragua, el relieve, la localización de complejos industriales, la viabilidad, actividades comerciales, agrícolas y ganaderas. Así como la migración, por ejemplo, del campo a la ciudad.

\section{RESUMEN}

This article is based on the author's doctoral thesis, where the geographical factors that influenced the urban evolution of the historical central zone of the city of Tipitapa in the years 1946, 1969, 1996, 2000, 2018 and 2020 were identified. From the approach of geographic analysis, aided by the Geographic Information Systems, the description of land use, urban morphology, as well as the most representative natural and cultural elements of the urban structure, components of the urban landscape, is deepened. Type of qualitative research. The main results show that the geographic factors that influenced the development of the historical central zone of the city of Tipitapa are the strategic geographic location in relation to the northern and Pacific regions of Nicaragua, the relief, the location of industrial complexes, viability, commercial, agricultural and farming activities. As well as migration, for example, from the rural areas to the city.
RECIBIDO

$26 / 03 / 2021$

ACEPTADO

$04 / 10 / 2021$

\section{PALABRAS CLAVE}

Factores geográficos; evolución; zona central; ciudad.

\section{PALABRAS CLAVE}

Geographic factors; evolution; central zone; city. 


\section{INTRODUCCIÓN}

El propósito del artículo es mostrar un recorrido por la zona central histórica de la ciudad de Tipitapa en los años 1946, 1969, 1996, 2000, 2018 y 2020 donde se identifican los factores geográficos que contribuyeron a su evolución urbana. Este tópico de investigación responde al Plan Nacional de Desarrollo Humano de Nicaragua 2018-2021, creado y asumido por el Gobierno de Reconciliación y Unidad Nacional (GRUN), con el propósito de unir esfuerzos en medio de la diversidad para hacer una nueva Nicaragua que supere la pobreza, dentro del marco del nuevo modelo de desarrollo alternativo del Poder Ciudadano, dado que el municipio, por lo tanto, las ciudades son espacios de desarrollo humano.

Asimismo, tiene un valor práctico de los Sistema de Información Geográfica (SIG) en la planificación urbana porque se han convertido en una herramienta para el análisis geográfico. La causa principal de esto reside en la multitud de actividades en las que pueden ser útiles, como la gestión y descripción del

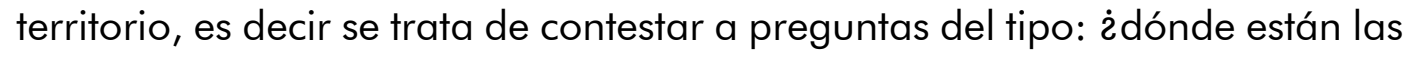
"cosas"? En este caso, permite la localización y espacialización de elementos territoriales de referencias, como lugares de interés público en la ciudad, con los cuales, los habitantes hacen memoria y se sienten identificados (Bosque \& C. García, 2000).

Por otra parte, existen investigaciones de referencia, como el estudio de Ingram Alfaro y Esteban Moreira (2013), sobre el análisis de la evolución urbana de la ciudad de Jinotepe en los años 1883-2012. Uno de sus objetivos, fue determinar los principales factores que influyeron en el desarrollo de la estructura urbana mediante el análisis de los instrumentos de planificación utilizados en 1883-2012.

Dentro de los resultados del estudio anterior, se determinaron las características más importantes de la evolución urbana de Jinotepe, tales como: la participación de la población en los proyectos de construcción de equipamiento urbano en el primer periodo (1883-1936); las grandes influencias políticas en el desarrollo de la ciudad en el segundo periodo (1937-1978); el auge del cultivo del café; las afectaciones del terremoto de Managua en 1972, despale indiscriminado de los bosques, la revolución sandinista, el desarrollo del turismo, el crecimiento urbano sin instrumentos de planificación y finalmente la consolidación de la infraestructura vial y equipamiento urbano durante el tercer periodo (1979-1990) y, cuarto periodo (1990-2012), donde se destaca la aparición del primer plan de desarrollo urbano como consecuencia de la expansión urbana.

Asimismo, Álvarez Arzate (2000) desarrolló una investigación sobre la ciudad ausente, políticas urbanas y espacios de socialización: paradojas de una 
ciudad. Donde realiza un esbozo de la evolución de las políticas urbanas y cómo estas repercuten en la morfología de la capital de Nicaragua en el año 2000. En este sentido, se señala que la ciudad de Managua del año 2000 es el espacio donde se desarrollan complejas relaciones sociales, culturales, políticas y económicas, de personas con diferentes procedencias geográficas, diversas concepciones acerca de sí mismo, de los otros y de intereses y motivaciones de vida muy diferentes.

La autora concluye que Managua es una ciudad ausente en los términos antes descritos, por lo tanto, se está ante una ciudad abstracta, metafísica, que solamente es vista y comprendida por sus habitantes. A los ojos y percepción de los "extraños" es difícil y lento llegar a conceptualizarla.

\section{Ciudad y evolución urbana}

Respecto a la evolución urbana, es importante señalar que se considera importante analizar el espacio urbano como tal, los usos de suelo y estructura urbana, los elementos naturales y culturales que se encuentran en el entorno geográfico, los aspectos políticos que han intervenido en su desarrollo y la influencia socioeconómica.

Antes de desarrollar el aspecto de la evolución urbana se precisa el concepto de ciudad, ya que existen definiciones de diversos autores de distintas disciplinas científicas. Respecto a este punto, Gómez Romero (2014), plantea que la ciudad es el lugar geográfico donde se instala la superestructura político-administrativo de una sociedad que alcanzado un punto de desarrollo tecnológico y social de orden natural y cultural que existe una diferenciación del producto en reproducción simple y amplitud de la fuerza de trabajo.

Los autores Ingram Alfaro y Esteban Moreira (2013) definen a la ciudad como el establecimiento físico, espiritual y cultural en donde las personas que lo habitan, se relacionan, se reproducen, sobreviven y se transforman. Cada ciudad tiene distintas expresiones físicas, dependiendo del concepto que tenga la población que la habita, de sus tradiciones culturales, medio geográfico, localización, entre otros. La definición del límite entre la ciudad y el campo, suele ser una tarea complicada, sin embargo, se puede decir, que la ciudad se distingue del campo por las siguientes razones:

- Concentración de población con una mayor densidad poblacional, así como la concentración de equipamiento, infraestructura y actividades que ofrece servicios y demanda de mano de obra.

- Concentración de actividad industrial, así como los centros de distribución y comercio, provisión de servicios, educación, salud, cultura, recreación, centros administrativos y financiamiento.

- El abastecimiento de servicios y mejores opciones de empleo y recreación. 
La ciudad es el espacio geográfico formado por un sistema complejo de elementos de infraestructura física, organización política-administrativa y base económica donde reside un alto número de habitantes que comparten similitudes en sus tradiciones culturales (Ingram Alfaro \& Esteban Moreira, 2013).

Otro concepto que está vinculado de forma directa es la evolución urbana de la ciudad. En primer lugar, se mencionan los distintos conceptos del término evolución, donde se concibe a la evolución como la acción de desarrollo o transformación de un estado a otro de forma gradual. Otro punto es que la misma, se suscita como un efecto, es decir, que existen agentes externos que provocan el proceso de evolución como tal. Por otra parte, el análisis del término evolución por sí solo no es suficiente, por lo tanto, es necesario comprender la definición de evolución urbana; pero antes es importante entender lo urbano como un aspecto inherente o relativo a la ciudad (Ingram Alfaro \& Esteban Moreira, 2013).

El crecimiento está vinculado al territorio, así como al grupo de ciudades con las que el centro urbano comercia. Una ciudad inicia su crecimiento cuando empieza a exportar y crecerá tan firme como lo sean sus exportaciones. Para que el crecimiento de un centro urbano sea sostenido es necesario que las innovaciones produzcan una vigorosa adición de nuevos empleos sobre la base de un creciente número de organizaciones económicas (Acuña Vigil, 2005).

Cuando se emplea el término desarrollo urbano es común referirse al desarrollo económico, cultural y social, además que hace referencia a la seguridad ciudadana, al medio ambiente, al transporte público y mejoramiento vial. Por lo tanto, la evolución urbana es el proceso de cambios progresivos causados por el desarrollo económico, político y social, así como los fenómenos naturales que afectan el medio geográfico, lo cual provoca el surgimiento de leyes, reglamentos y planes reguladores que ayudan a evitar el crecimiento desordenado de la ciudad.

\section{Desarrollo urbano local}

Para desarrollar este aspecto, se hace referencia en primera instancia al desarrollo local, porque el desarrollo urbano tiene como base fundamental los modelos de desarrollo que se implementen en el territorio. En principio, los objetivos básicos de toda sociedad, apuntan a lograr un desarrollo común para todos sus miembros, en sus diversas dimensiones.

Conceptualmente, el término desarrollo es definido en su acepción económica como la evolución progresiva de una economía hacia mejores niveles de vida, acepción que parece ser la más arraigada entre las altas esferas de poder y la más difundida por los gobiernos locales. Sin embargo, y según diversos autores, el desarrollo debe ser entendido como un medio y no como un fin. 
Con respecto a lo anterior, el desarrollo es como "logro de un contexto, medio, situación, entorno o como quiera llamarse, que facilite la potenciación del ser humano para auto transformarse en persona humana, en su doble dimensión: biológica y espiritual, capaz en esta última condición de conocer y amar" (Boiser, 2003). Así mismo, este autor plantea que el propósito central de toda propuesta de desarrollo no puede ser otro sino "otorgarles a los seres humanos su dignidad como personas, en un marco de valores en el cual la libertad, la democracia, la justicia, la ética, la estética, la solidaridad y la variedad constituyen sus elementos definitorios.

Por consiguiente, este enfoque de desarrollo supone ubicar a los seres humanos en un tejido social que se debe de densificar y articular hasta que se transforme en una verdadera comunidad, es decir, en una asociación de personas que basan su asociatividad en la "razón natural", esto es, en la emocionalidad y en un sentido de pertenencia. Se debe crear una comunidad con un fuerte sentido de identidad.

Por otro lado, se tiene que tener en cuenta el carácter subjetivo del desarrollo, resulta imprescindible cuantificar, potenciar y articular los diversos capitales intangibles que genera el desarrollo. Debiendo ser ejecutado todo este operativo del desarrollo, de forma endógena. Por otra parte, (Gallicchio, 2020), señala que el desarrollo local es una estrategia para alcanzar el desarrollo, no un paradigma. Corresponde a un proceso orientado que surge como una ruta diferente y alternativa de desarrollo nacional y regional, constituyendo una nueva manera de comprender y construir cada país (Moraga López, 2010).

En términos generales, el autor citado anteriormente conceptualiza el desarrollo local como un proceso de concertación entre los agentes-sectores y fuerzas que interactúan en un territorio determinado, para impulsar, con la participación permanente, creadora y responsable de ciudadanos y ciudadanas, un proyecto común de desarrollo que implica la generación de crecimiento económico, equidad, cambio social y cultural, sustentabilidad ecológica, enfoque de género, calidad, equilibrio territorial con el fin de:

Figura 1. Implicaciones del desarrollo local

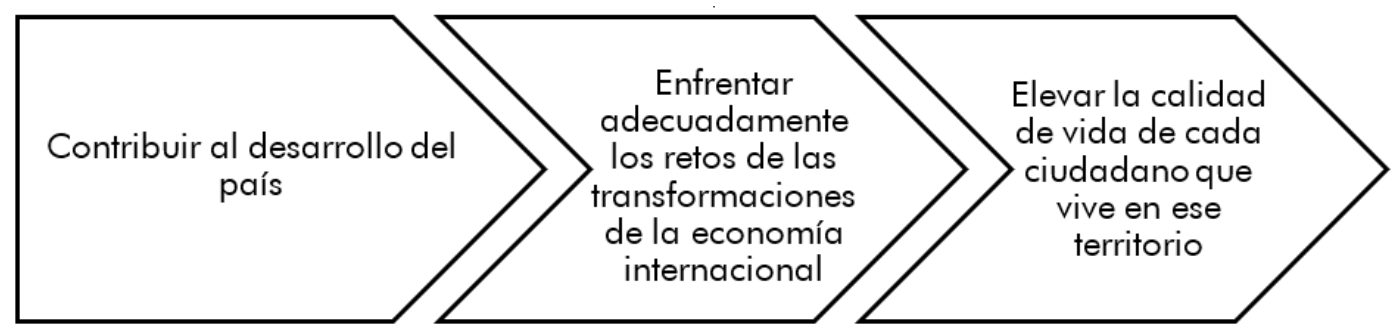

Citado en (Moraga López, 2010) 
Por otra parte, es un requerimiento fundamental del desarrollo local, la presencia activa de una identidad cultural local capaz de manifestar sus acciones e inquietudes. Al respecto, señala que "una de las piedras angulares de un proceso de desarrollo local es el fortalecimiento de la identidad y la cultura local.

El dinamismo, la creatividad y la energía que nutren el desarrollo local provienen de un nuevo sentimiento de pertenencia de los ciudadanos respecto de su localidad. La afirmación de un sentir colectivo de autoestima que fortalece la identidad local, permite a los ciudadanos relacionarse entre sí y con otras localidades en un espíritu de mayor armonía, con un nuevo sentido de confianza y seguridad. El desarrollo local comienza a partir de la afirmación de quiénes somos, de dónde venimos, a qué pertenecemos y que nos distingue (Moraga López, 2010).

Un aspecto importante que no se debe de omitir en el tema de desarrollo local es la modernización, cabe destacar que existe una diferencia conceptual entre los términos concernientes a la modernidad, de este modo el concepto modernidad se presenta como una etapa histórica; modernización como proceso socioeconómico que trata de ir construyendo la modernidad, y modernismo como proyectos culturales que renuevan las prácticas simbólicas con un sentido experimental o crítico.

Con respecto al párrafo anterior, la modernización surge como un fenómeno desestabilizador en la construcción de la identidad, generando impactos en el eje social, alterando las dinámicas de transformación social, cultural, la concepción y el sentido de pertenencia hacia el territorio (Rozas, 1997). Por otro lado, los conflictos entre la modernidad y el territorio desde un análisis regional. Su perspectiva propone un punto de vista más beneficioso de esta relación, en términos económicos, donde la cultura y la identidad asociadas al territorio hoy se revitalizan, no sólo como valores intrínsecos, sino como factores de competitividad regional (Boiser, 1996).

Las sociedades demandan la existencia de elementos comunes que los convoquen. Se trata de espacios físicos, territorios colectivos que permitan el encuentro entre las personas. Eso aparece como una base indispensable, un escenario básico para el desarrollo de cualquier tipo. Pero simultáneamente se aspira a la existencia de un sentir común, algo que define un "nosotros" que llene de contenido esos espacios. Pareciera subyacer la noción de que la existencia de esos espacios no genera por sí sola una identidad común.

Con relación al punto anterior, el Informe sobre Desarrollo Humano del Programa de las Nacionales Unidas para el desarrollo (2013), plantea que, para que el encuentro en los espacios comunes del barrio, de la ciudad y del entorno natural produzca integración, se requerirá de la existencia de una identidad cultural, ya que entre integración espacial y pertenencia cultural habría un mutuo reforzamiento. Muchos de los proyectos y estrategias 
propuestos para el desarrollo de comunidades, obvian la relación conflictiva que se presenta entre los procesos de modernidad y cultura tradicional generando impactos negativos y malas experiencias en la intervención de los territorios y sus comunidades.

En pocas palabras, el desarrollo local en la práctica se centra en procesos económicos generadores de empleo, y en su versión más simple, este desarrollo no incluía un concepto que fue integrado con el tiempo para nutrirlo: el concepto de territorialidad, para establecer así el término "desarrollo territorial", concepto más amplio que el simple desarrollo local al proponer la importancia de los factores territoriales tangibles, tales como los atributos físicos y los factores territoriales intangibles, tales como organización social, cultura y tradiciones.

El modelo de desarrollo territorial tiene por objetivo, establecer en un territorio determinado un modelo de desarrollo cooperativo, sustentable y equilibrado con un profundo sentido de identidad.

Los factores que promueven la identidad crean un esquema de auto sostenibilidad dentro del desarrollo, dado que la identidad otorga el sentido de comunidad territorial y refuerza la solidaridad y sentido de colectividad. Hace que los habitantes de una comunidad se comprometan con el proyecto haciéndolo realmente suyo. Rompe el carácter provisional, otorgando la atemporalidad y continuidad en el tiempo (Doval, 2004).

De la misma forma, entre los elementos que conforman la identidad local se encuentran los siguientes:

Figura 2. Elementos que conforman la cultura e identidad local

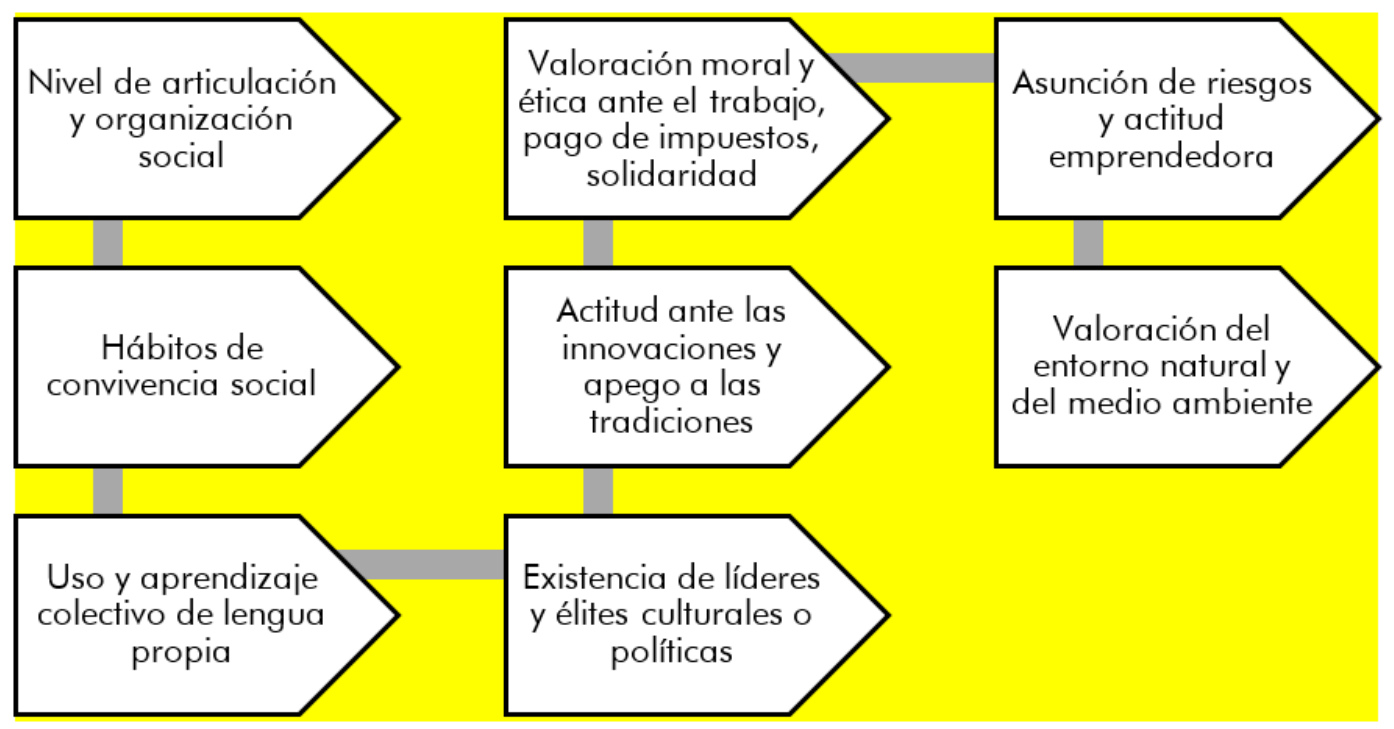

Fuente: (Doval, 2004). 


\section{Estructura urbana}

El otro concepto que está relacionado con el tema de investigación, es la estructura urbana. En este sentido, la forma urbana permite observar la forma de la ciudad, si es concéntrica, si tiene una tipología o geometría controlada.

Como el subnivel de la estructura urbana, el cual está compuesto por seis elementos, pero en este estudio se retomaron los tres siguientes :

- El contorno, constituido por la peculiar forma geométrica que adopta el perímetro delimitado por el crecimiento urbano. Así mismo, se define como el perímetro que describe las aglomeraciones urbanas.

- La traza es la pauta que describe las calles y las manzanas. También se le denomina red vial. Es el diseño básico de la ciudad tradicional de la ciudad tradicional que se suma de calles y casas, sigue siendo el esqueleto o la estructura formal en la que las partes se organizan como un todo.

- La forma de las manzanas, como su nombre lo indica, es la forma que adoptan las manzanas en dependencia de la traza. Las formas de las manzanas pueden ser cuadradas, rectangulares, triangulares 0 irregulares.

La estructura urbana no debe simplificarse como la estructura geométrica de la trama urbana, sino que es un concepto mucho más completo que debe contemplar, entre otros parámetros, su adecuada inserción con las estructuras urbanas de su entorno. Esta se entiende como la relación entre la organización espacial de las actividades urbanas y el conjunto de elementos físicos que configuran el área urbana y cuyas características, organización y distribución permiten el funcionamiento de un poblado. Los elementos que conforman la estructura urbana se interrelacionan entre sí, de forma dinámica e interdependiente, formando una unidad funcional en la cual, si se afecta uno de estos elementos, habrá repercusiones en los demás. Sus principales componentes son (Ingram Alfaro \& Esteban Moreira, 2013, págs. 7-10):

- Usos de suelo, que se refiere al ordenamiento de los elementos ya actividades urbanas o regionales por sectores parciales o zonas, en función de sus características similares y con el propósito de lograr mayor eficacia en su utilización y funcionalidad dentro de la misma estructura.

- Vialidad. Es el sistema vial o la red de vías de comunicación terrestre, como las calles, caminos, avenidas, carreteras, autovías, autopistas, entre otros) jerarquizadas y utilizadas por los habitantes para desplazarse entre zonas, ciudades y localidades.

- Equipamiento urbano que está referido al conjunto de edificaciones y espacios, predominantemente de uso público, en los que se realizan actividades complementarias a las de habitación y trabajo, o bien, en las que se proporcionan a la población servicios de bienestar social y 
de apoyo a las actividades económicas. En función de las actividades o servicios específicos a que corresponden se clasifican en equipamiento para salud, educación, comercio y abastos; cultura, recreación y deporte; administración, seguridad y servicios públicos.

No obstante, cuando algún componente de los mencionados anteriormente es identificado por un número considerable de habitantes, este pasa a ser un elemento de la imagen urbana de la ciudad. La imagen urbana se refiere a la conjugación de los elementos naturales y culturales que forman parte del marco visual de los habitantes de la ciudad, en interrelación con las tradiciones culturales y uso del espacio por sus pobladores, además por el tipo de actividades que se desarrollan en ella (Ingram Alfaro \& Esteban Moreira, 2013, págs. 7-10).

\section{El lugar y espacio geográfico}

El lugar juega un papel importante en la memoria y żqué es el lugar? El lugar es la unidad básica de la geografía, es como el átomo del espacio geográfico. El espacio geográfico se compone de una multitud, de una infinidad de lugares. Éstos se definen por su posición y su forma en una escala determinada (Augé, 1992).

Por otra parte, la posición del lugar es única (latitud, longitud y altitud) y no se modifica por el cambio de escala. La forma se define gracias a los tres elementos básicos en geografía: punto, línea y superficie. La escala de percepción o de estudio puede modificar la forma como el elemento asociado al lugar: una ciudad puede ser un punto perdido en el mundo o una superficie con elementos asociados internos. Por consiguiente, el lugar se distingue de la localización porque sitúa a este primero. La localización introduce la noción de diferencia, de relatividad: un lugar no es necesariamente igual a otro. La localización es, entonces, un acto social de inscripción de un lugar en la especificidad: ¿̇Dónde está?, ¿̇cómo está?, ¿̇cómo se diferencia? ( Mazurek, 2009).

El geógrafo Milton Santos explica que el objeto geográfico tiene autonomía de existencia que proviene de su materialidad, pero que no tiene autonomía de significado. Se necesita, entonces, distinguir entre "el ser-objeto" y el "valer como objeto", el valor absoluto del objeto y su valor sistémico con relación a un sistema de objetos. En este sentido, el espacio es testimonio de la realización de la historia, a través de la dinámica de los lugares y de su significado, la localización (Mazurek, 2009).

En cada lugar existe un eje temporal de sucesión de eventos sociales que permite hablar de hoy, ayer y mañana; pero en la experiencia cotidiana de la humanidad, los eventos no son sucesivos, son concomitantes: existe una sincronía de las acciones y de la percepción de los actores en el espacio. Por supuesto, este modelo espacio-temporal tiene flujos y ritmos diferenciados 
que también forman parte de los parámetros de la localización. Con respecto a este punto, Santos (2009), plantea lo siguiente:

Cada localización es, pues, un momento del inmenso movimiento del mundo, aprehendido en un punto geográfico, un lugar. Por eso mismo, gracias al movimiento social, cada lugar está siempre cambiando de significado: en cada instante las fracciones de la sociedad que incorpora no son las mismas (pág. 148).

El espacio geográfico es un tejido de localizaciones, tiene una estructura por la organización de las localizaciones y es un sistema porque existen relaciones entre las localizaciones. El espacio geográfico es entonces una porción concreta de la superficie terrestre que puede ser considerada, a una escala determinada, en su conjunto, en cada uno de sus lugares, en sus relaciones internas y en sus relaciones externas con los demás espacios ( Mazurek, 2009). El espacio implica una serie de relaciones de coexistencia explicadas desde diferentes perspectivas, en donde se dan los vínculos, las relaciones e interacciones, que llevan a la construcción, transformación, percepción y representación de la realidad (Ramírez Velázquez \& López Levi, 2015).

En geografía, todas relaciones de coexistencia se expresan mediante factores, tales como: localización, ubicación, distancia, superficies o zonas, dirección, rumbo, áreas de influencia, responsabilidad, dominio, resistencia, forma, tamaño, posición (centro-periferia, interno-externo, cerca-lejos, norte-sur), distribución, vecindad, accesibilidad, procesos de aglomeración y dispersión, patrones, nodos, flujos y rutas.

Todo lugar tiene una ubicación. Sin embargo, el "dónde" va más allá de la geometría, de las coordenadas geográficas (latitud, longitud y altitud), y puede ser representado por una variedad de categorías: el "reconocido" (toponimia, valor simbólico atribuido, etc.), el hábitat (parcela, medio particular, un clima, una plaza, una cumbre, etc.) o la vivienda (una iglesia, una casa, un barrio, una cuadra). Está claro que la sociedad no atribuye una coordenada a los lugares donde vive o donde actúa. Es el valor que la sociedad atribuye al lugar lo que constituye la base de la ubicación de ese lugar (Mazurek, 2009).

\section{Mapa de la evolución urbana}

El mapa es una herramienta imprescindible para la ubicación espacial de los acontecimientos y procesos, es además un registro de la memoria de las actividades y acciones de los seres humanos en el tiempo y espacio. Los mapas son una fuente de gran importancia para el conocimiento de aspectos geográficos e históricos del territorio, pues frecen una "fotografía", 
estática o dinámica, de algún acontecimiento o proceso ocurrido en el medio geográfico.

Para el análisis de la información del mapa fue necesario realizar los siguientes pasos: En primer lugar, se identificaron los siguientes elementos básicos del mapa, tales como: título, fecha y tipo de mapa, escala, sistema de proyección, rotulación, colores y cartela. En segundo lugar, se descodifica la información con el auxilio de los símbolos contenidos en la leyenda.

Respecto al análisis de los mapas modelo de la evolución urbana de la zona central histórica de la ciudad de Tipitapa de los años 1946, 1969, 1996, 2000, 2018 y 2020 se realizó un análisis diacrónico que consistió en los siguientes momentos: El primer momento consistió en la identificación y descripción del mapa, que consiste en precisar aspectos formales como el título y tipo del mapa, la tipología gráfica y aspectos expresivos, el sistema de signos y leyenda, cuya disposición sobre el plano expresa en muchas ocasiones la claridad con que el investigador ha sabido desarrollar el tema planteado. También, se señala la situación del mapa en el espacio y tiempo.

El segundo momento, se realizó el análisis del mapa que consistió en hacer una introducción del momento histórico que representa. Por otro lado, se diferencian los conjuntos espaciales, barrios, se observaron los trazados de las vías de comunicación, rutas, principales edificios, entre otros, y se establecieron las relaciones respectivas. También, se realizó una búsqueda de ideas principales relacionadas con el título del mapa e ideas secundarias referidas a la explicación de acontecimientos que se reflejan en el mapa. Y el tercer momento comentario del mapa. Se inicia con la determinación del escenario, la datación de los acontecimientos y el lugar.

\section{MATERIALES Y MÉTODOS}

Esta investigación es de tipo descriptiva. Es transversal y retrospectiva. Las técnicas utilizadas para la recopilación de los datos fueron la revisión documental y análisis diacrónico de mapa modelo. En cuanto a las etapas de la investigación, en primera instancia se realizó una revisión de documentos referidos a datos históricos e institucionales y, en segundo lugar, se realizó la elaboración de mapas.

La confección de los mapas consistió en primer lugar, en la ubicación y delimitación del área geográfica de estudio, así mismo se precisaron los lugares de interés dentro de los barrios de la zona central de la ciudad de Tipitapa, así como los años. En cuanto al tiempo (años de los mapas), estos se establecieron con base a las fotografías aéreas e imágenes de satélites a 
las cuales se tuvieron acceso. Se hizo una tabla para especificar el nombre de los lugares y los años tomados en cuenta. En segundo lugar, se procedió al trabajo de campo para el levantamiento de los lugares de interés como edificios o zonas representativos ubicadas dentro de los barrios. Se definió el sistema de proyección WGS84 UTM zona $16 \mathrm{~N}$, correspondiente a la mayor parte del territorio nacional.

En tercer lugar, se procedió al procesamiento de los datos de campo, donde se descargaron los puntos y líneas, que permitió agregar atributos de cada elemento. Asimismo, se realizó la búsqueda, descarga y georreferenciación de imágenes satelitales de alta resolución espacial. Por otra parte, se procedió a la descarga de los puntos del GPS mediante el programa ExpertGPS4.83, el cual convierte los puntos de gpx a shp para facilitar su manipulación.

Una vez los datos convertidos, fueron descargados en el programa ArcGIS 10.4, sistema que permite recopilar, organizar, administrar, analizar, compartir y distribuir información geográfica, donde se efectuó el ingreso de los atributos en la tabla de atributos para lograr la identificación con mayor facilidad de los elementos que se encontraron en el terreno, cabe mencionar que esta tabla varía según los años.

Luego, se procedió a la georreferenciación que es la técnica de asignación de coordenadas geográficas a un objeto, que se utiliza en los procedimientos de cartografía informatizada y en la elaboración de bases de datos cartográficas digitales. Se procedió a la georreferenciación que consistió en añadir un sistema de referencia a ortofotomapas que es una sub-escena de un ortofotomosaico a la cual se adiciona la toponimia y algunos vectores que representan los elementos planimétricos, sobre dicho ortofotomapas se pueden realizar mediciones con las precisiones similares a las del mapa vectorial, dado que estos no poseían un sistema de referencia.

Con respecto al párrafo anterior, las imágenes que no poseen un sistema de referencia o no estén georreferenciadas es necesario aplicar la rectificación que es el proceso de proyectar los datos en un plano de acuerdo con un sistema de proyección cartográfica. La asignación de coordenadas de mapa a una imagen se conoce como georreferenciación. Debido a que todos los sistemas de proyección cartográfica están asociados con coordenadas de mapa, la rectificación incluye la georreferenciación (MappingGIS, 2021).

La georreferenciación de las imágenes de los años 1946, 1969 y 2000 se hizo mediante la extensión Georeferecing del programa ArcGIS 10.4, en promedio se obtuvo un error residual de 3.5 el cual es bueno, ya que el tamaño del pixel es menor a 3 metros. Cabe mencionar que las imágenes de los años 1996 y 2018 ya poseían sistema de referencia. En el caso de las imágenes del año 2000 se tuvo que realizar un mosaico con las dos imágenes que cubrían la zona de estudio, este proceso se hizo con el módulo Mosaic de Erdas Imagine versión 2014. 
El primer mapa de uso de suelo realizado fue del año 2018, por lo tanto, conviene subrayar, que, en la imagen de ese año, se dejaron caer los puntos de referencia y se inició el proceso de fotointerpretación y digitalización de los elementos encontrados en la zona de estudio previamente definida, una vez finalizado este mapa se tomaron como referencia el shapes de carreteras para hacer el proceso de georreferenciación.

Una vez terminado los procesos de referenciación y la realización del mosaico se procedieron a hacer el mismo proceso de fotointerpretación y digitalización que consistió en el proceso de convertir las entidades a un formato digital, para la creación de los datos. Existen varias formas para digitalizar nuevas entidades. Estas incluyen digitalizar en pantalla o con pantalla integrada sobre una imagen, digitalizar una copia impresa de un mapa en un tablero de digitalización o utilizar la digitalización automatizada, en este caso se utilizó la automatizada.

La digitalización de los elementos encontrados en las imágenes junto con la incorporación de los puntos de referencia varía según los años; esto permitió mostrar el cambio que ha venido sufriendo el área de estudio según el paso de los años junto con el crecimiento poblacional.

Finalmente, se procedió a la realización del diseño de impresión de los mapas de uso de suelo de los distintos años, el cual inicio con la definición de los estilos para los diferentes elementos, del mismo modo se definió la escala para los cinco mapas, la cual fue 1: 15,000 $(1 \mathrm{~cm}$ en el mapa equivalen a 150 metros en el terreno), además se agregaron los elementos básicos del mapa, tales como: título, logo, escala, leyenda y ubicación. De igual forma, se efectuó la exportación del proyecto del software ArcGIS 10.4 a formato JPEG con 300 dpi para una mejor resolución.

Para el análisis de los mapas-modelo de la evolución urbana que comprende los años 1946, 1969, 1996, 2000, 2018 y 2020, se establecieron en periodos. Un primer periodo que abarca los años 1946 y 1969 , el segundo 1996 y 2000 y el tercero 2018 y 2020 . En cada uno de los periodos, se muestra los usos de suelo, elementos de la morfología urbana, así como los elementos naturales y culturales representativos del paisaje urbano. 


\section{RESULTADOS Y DISCUSIÓN}

\section{a) Primer periodo: 1940 y 1969}

\section{Uso de suelo}

Previo a este período, es importante destacar que Tipitapa fue antiguamente una población aborigen, perteneciente a la alargada ciudad de Managua, ocupando el extremo norte de esta, donde residía el cacique que llevaba su nombre. Muchos historiadores opinan que esta población indígena se localizaba desde La Garita en el km 15 de la carretera Panamericana norte hasta el barrio La Bocana. Sus primeros pobladores fueron los Chorotegas, por su ubicación geográfica eran conocidos con los nombres de Dirianes y Nagrandanos. Los Dirianes tenían como principales poblaciones: Xalteva, Diriomo, Niquinohomo, Jinotepe, Diriamba, Masatepe, Masaya, Nindirí, Managua, Tipitapa y Mateare (Alcaldía Municipal de Tipitapa, 2005).

La villa San José de Tipitapa, como se llamaba en la época de la colonización, mantenía una plena dominación por parte de los españoles, debido a su ubicación geográfica, bordeado por el Lago de Managua y el río Tipitapa, que en esa época era navegable y comunicaba a los dos lagos por la vía del Paso de Panaloya hacia el Lago Cocibolca o de Nicaragua hasta llegar a la orilla de Granada. Según las crónicas españolas recopilada por los historiadores Gratus Halftermeyer y Julián Guerrero que plantean que el encomendero Juan Bautista Almendarez fundó el poblado de Tipitapa en 1755, ubicado donde es hoy el Parque Central Buenaventura Navarro, compuesto por la Iglesia, el edificio del cabildo, algunos ranchos de paja y una calle o camino de tierra entre la iglesia y el caserío, además el primer puente de tablas para cruzar el río Tipitapa, el cual tenía una longitud de 208 metros (Alcaldía Municipal de Tipitapa, 2005).

En Tipitapa se efectuaron batallas significativas, una de ellas a poca distancia de su pueblo en la Hacienda San Jacinto. En este lugar se dio inicio a la liberación del territorio nacional de los invasores norteamericanos. Por otro lado, el acontecimiento más importante de la ciudad de Tipitapa es el Pacto del Espino Negro, celebrado el 4 de mayo de 1927, entre las facciones liberales y conservadoras, que se encontraban en disputas y guerra civil por el poder político de Nicaragua. El lugar donde se dio este hecho se localiza en el espacio donde se ubica la Plaza de la Dignidad Sandinista., frente a la casa municipal de la cultura.

En ese mismo año (1927) existían 500 casas en la ciudad de Tipitapa. La ciudad poseía una forma alargada como escalera con dos calles largas (de norte a sur) y numerosas vías o calles cortas, de este a oeste, desde el empalme sur hasta la orilla del río. Este alargamiento lo conserva hasta 1956 
y 1961. Además, en estos años se produjo una inundación, específicamente en el sector de La Bocana (Noel Morales 4), que causó daños similares a los del posterior huracán Mitch (Alcaldía Municipal de Tipitapa, 2005).

En 1929 por decreto oficial, Tipitapa recibió el nombre de Villa Stimpson, debido a hechos políticos ocurridos en este lugar (pacto del Espino Negro). En 1933 se produjo otra inundación producto de una crecida del río Tipitapa, que ocasionó desórdenes de índole demográfica y marcó el crecimiento de la ciudad (Alcaldía Municipal de Tipitapa, 2005).

Respecto al uso del suelo que se tiene del primer periodo es muy poca, sin embargo, con el ortofotomapa del año 1946 se logró identificar distintos usos de suelo. En este sentido, los datos de uso de suelo del año 1946 (figura 1) indican un predominio de cultivos (algodón, sorgo, ajonjolí) con 213 ha, seguido por matorrales ( $111 \mathrm{ha}$ ), por el casco urbano (46 ha), por pasto (21 ha), y a poca distancia por tacotal (9 ha). Por lo tanto, en el área de estudio básicamente abundaban las áreas de cultivos y matorral, seguido por el casco urbano, siendo el tacotal una parte poco significativa del territorio para ese año.

En detrimento de los cultivos de 213 ha, en 1946 se pasó a 166 ha, en 1969 (figura 2), sin embargo, el área del casco urbano aumentó, de 46 ha en 1946 a 77 ha en 1969, así mismo se observa la cobertura de matorral que de 21 ha en 1946 incrementó a 31 ha en 1969, el área de tacotal disminuyó por completo en el año 1969. Este crecimiento de los cultivos en la zona de estudio se debió principalmente al inicio del auge del algodón, uno de los rubros importantes de la economía nacional (Belli, 1975).

Sumado a lo anterior, el poblador Bodan expresó "Como usted sabe, Tipitapa nació como un puerto de carreteras que se alimentó de la agricultura en ese tiempo, del algodón, que es lo que hace nacer a Tipitapa" (Tapia, 2018).

Un dato de referencia interesante a tener en cuenta para el periodo 19461969 es que desde los primeros años del siglo XX (inicio de 1900 en adelante) siguieron funcionando las grandes haciendas ganaderas, potreros, corrales para ganado, chiqueros para cerdos, granjas avícolas para la producción de gallinas, chompipes, pájaros como loras y chocoyos, por ejemplo, una de las haciendas fue la llamada La Palmita que se extendió desde el sur del parque central de Tipitapa y un poco más allá de donde hoy se ubica el Complejo Penitenciario Jorge Navarro o cárcel La Modelo (Barreto, 2002, págs. 4853).

En cuanto a la población del casco urbano, incrementó de 1946 a 1969, no se conoce con exactitud la cantidad de habitantes para el año 1946. Con respecto a lo anterior, el Plan Maestro de Desarrollo Urbano de la ciudad de Tipitapa 2004-2024, muestra cifras de población a partir del año 1963, donde la población del área urbana fue 3,600 habitantes que representa el 
$24 \%$ del total de población urbana, el otro porcentaje corresponde al área rural, indicando que en Tipitapa había predominio del área rural.

A pesar de no contar con los datos exactos de población de 1946, se puede apreciar en las figuras 1 y 2 que el área urbana incrementó, lo cual se ve reflejado en un aumento de los suelos residenciales y de la red de calles tanto principales como secundarias. Por otro lado, el área de los barrios Noel Morales y Roberto Vargas incrementó durante dicho periodo, de 34 ha en 1946 a 48 ha en 1969.

Es importante destacar que dentro de las causas del incremento de la población fueron debido al fuerte movimiento pendular de la población de Managua hacia Tipitapa por razones de búsqueda de empleo, desastres de origen naturales y antrópicos. Por lo demás, la década de los años 60 y 70 estuvo marcada por el fenómeno industrial con el desarrollo de la industria ligera, en los años 80 se impulsó el proyecto del Ingenio Victoria de Julio. Hecho que se revierte en la década de los años 90 con el proyecto de Zonas Francas en Managua y Masaya.

El tejido urbano continuó experimentando un crecimiento, pasando de 46 ha en 1946 a 77 ha en 1969. En el mapa de 1946 es posible diferenciar los límites del casco urbano de Tipitapa, bordeados por campos de cultivos, matorrales y pasto hacia el sur este y oeste (figura 2). Posteriormente, la zona urbana de Tipitapa se prolongará en dirección sur, este y oeste (figura 3). En este periodo, Tipitapa era llamada Villa Stimpson (elevada a villa en 1929) y estaba conformada por dos barrios: La Bocana (llamado Noel Morales 4 actualmente) y Roberto Vargas Batres.

En cambio, en 1969, Tipitapa ya había sido elevada a ciudad por decreto presidencial No. 620 aprobado el 30 de agosto de 1961 y presentaba nuevos barrios, tales como: Noel Morales 4 (barrio La Bocana anteriormente), Noel Morales 5 y Teófilo Rivas (Alcaldía Municipal de Tipitapa, 2005). Por otra parte, el mapa de 1946 presenta que el contorno de la ciudad de Tipitapa era de tipo cerrado, característicos de las ciudades emplazadas en llanura, con forma ortogonal donde predominan las líneas rectas en el trazado de las calles, que se cortan perpendicularmente formando cuadrículas, con una gran sensación de orden.

\section{Morfología urbana}

La traza o trama de la ciudad era de cuadrícula, cuya configuración se debe a las características naturales del terreno y por consiguiente a la forma de la ciudad. En cuanto al diseño de las manzanas, se observó predominio de manzanas de forma cuadradas perfectas. En cambio, en el mapa de 1969, el contorno de la ciudad cambia con respecto al mapa anterior, se amplía y alarga hacia el noroeste y sur, sin embargo, el contorno sigue siendo de tipo cerrado, (característicos de las ciudades ubicadas en llanura) y presenta 
forma ortogonal. En cuanto, a la traza de la ciudad siguen las cuadrículas con irregularidad en el sector noroeste (La Bocana), esto se debe al incremento del uso de suelo con fines habitacionales. En cuanto al amanzanamiento, se continuó observando predominio de manzanas de forma cuadradas, sin embargo, en la zona noroeste y sur ya no hay predominio del mismo patrón.

Respecto a las casas de la ciudad de Tipitapa, tenían un diseño colonial, construidas en su mayoría con arena, teja, talquezal y madera. Además, presentaban puertas y ventanas al lado de las calles, con dos puertas en la esquina para mayor ventilación, dándole así un mejor aspecto a la fachada de las viviendas.

\section{Infraestructura vial y accesibilidad}

En cuanto a la vialidad, la ciudad de Tipitapa en el año 1946, presentaba cinco calles principales paralelas en dirección norte a sur, entre ellas se destaca la calle principal localizada en el centro de la ciudad, que era el tramo de la carretera Panamericana (carretera interregional sistema de carreteras que vinculan a casi todas las regiones del país y por ende a los países del Continente Americano) que iniciaba desde el empalme en el sur hasta el río Tipitapa en el norte de la ciudad. Según Barreto (2002) la ciudad tenía una forma de escalera, porque era larga de norte a sur, con calles cortas que se atravesaban de este a oeste.

El casco urbano de Tipitapa posee dos puentes, el primero en la vía Panamericana, cerca del hotel Aguas Caliente y el segundo el puente El Diablo, localizado cerca de los Baños Termales. Por otra parte, para el año 1969, la ciudad incrementó el número de calles, de cinco a seis, esta nueva calle se agregó por el este del casco urbano. La vía Panamericana se localizaba en el mismo lugar que en el año anterior (centro de la ciudad). Las principales rutas de acceso a la ciudad en el periodo 1946-1969 fueron los mismos en ambos años, los cuales son:

- Desde la parte sur por medio de la carretera Panamericana que comunica al municipio de Tipitapa con la ciudad de Managua y los departamentos del norte y centro del país.

- Desde la parte sur por medio de un camino que conectaba al municipio de Tipitapa con la ciudad de Masaya.

\section{Actividades productivas}

En cuanto a la industria, el casco urbano de Tipitapa no contaba con lugares dedicados a esta actividad económica en 1946. En cambio, en el año 1969, presentaba La METASA, localizada al sur, la cual existe desde 1958, se dedicaba a la fabricación de perlinas, tensores, láminas metálicas. Esta empresa tuvo auge para la reconstrucción de Managua, después del terremoto. Otra fábrica destacada y que no se localizó precisamente en 
el casco urbano es La Plywood, ubicada en el km 15, en la orilla del río Tipitapa. Esta empresa existe desde 1961, cuando era común encontrar madera preciosa como caoba, pochote cedro real en la zona.

En cuanto al comercio, la ciudad de Tipitapa ha sido el lugar donde se ha concentrado la actividad comercial a lo largo de su historia, debido principalmente a su ubicación geográfica, esto lo ha convertido en un puerto comercial, donde han convergido comerciantes de varios departamentos del país. Al respecto Barreto (2002), señala que:

Tipitapa en los primeros años del siglo XX se producía una especie de capitalcentro del comercio entre productores y pobladores de Estelí, Matagalpa, Sébaco, Chontales y Boaco, con habitantes de Managua, Masaya y Granada. Estos productores del norte y oriente, por ejemplo, venían en carretas, mulas, en caballos y a pie hasta Tipitapa, trayendo consigo friijoles, maíz, trigo, cerdos, ganado, gallinas, gallos (...) todo lo cual era vendido en las tiendonas de los terratenientes y comerciante (...) (pág. 48).

Como se puede observar en las figuras 1 y 2, el casco urbano se desarrolló en el margen sur del río Tipitapa, para este período, la actividad comercial se concentraba en dos sectores, el primero a lo largo de la calle central, donde se localiza el mercado municipal; y el segundo en la calle que va en dirección de la Alcaldía Municipal hacia los Baños Termales. En estos existían establecimientos comerciales en mayor grado, tales como: pulperías, tiendas de mercadería general, ferreterías, venta de frutas, expendios de licor, venta de granos básicos, carnicerías, venta de lubricantes, panaderías y en menor grado funerarias, venta de respuestas y comercializadoras de café. También se destacan restaurantes como Entre Ríos y Silva, localizados en la calle central y que ofrecen el pescado sin espina (pescado a la Tipitapa) una de las comidas típicas de la ciudad.

La ciudad de Tipitapa presenta el parque central, que fue fundado en 1755 por el encomendero español Juan Bautista Almendarez. Este lugar fue el suelo original de la fundación del poblado de Tipitapa en 1755. También, existió un cementerio indígena antes de la fundación del cementerio actual, situado contiguo a METASA, que hoy es INDENICSA. Asimismo, se destacan Los Baños Termales, donde se localizan las fuentes de aguas termales, que fueron atracción de curiosidad por parte de españoles, indígenas y gringos, por las propiedades medicinales de sus aguas y para la diversión. Con respecto a los Baños Termales, Halftermeyer, (1946) señaló:

"En la vecina villa de Tipitapa, la puerta comercial de Managua, fue creado un balneario medicinal, aprovechando las fuentes de agua caliente azufrada, de origen volcánico que hay en el lugar. A la orilla de la gran piscina está un hotel para el refrigerio de los bañistas y alojamiento de enfermos. Ese lugar pintoresco atrae el turismo" (pág. 174). 
Por otra parte, sobresale el estadio de béisbol de La METASA, ubicado hacia el este de la empresa homónima. En cuanto a lugares con servicio de hospedaje, la ciudad contaba con los hoteles Aguas Caliente y Los Baños Termales.

La ciudad de Tipitapa no contaba con cementerio en 1946. En cambio, en el año 1969, aparece el cementerio, ubicado hacia el sur del casco urbano. Otro edificio que se destaca en este período es el complejo penitenciario Jorge Navarro, llamado por Anastasio Somoza García como Cárcel Modelo. Esta se construyó en la década del cincuenta y comenzó a funcionar como tal en los años setenta. Con relación a lugares religiosos, se destaca el templo de origen colonial San José de Tipitapa, ubicado en la calle central del casco urbano, frente al parque central. Este se construyó a principios del siglo XVIII, aproximadamente del año 1720.

Con respecto a lo anterior, Tapia (2018), señala que el templo San José de Tipitapa, al principio fue como una ermita porque era un lugar de paso para la gente que se dirigía hacia el norte del país, pero en el año 1720 se construyó el templo que hoy se conoce. En 1756 la imagen de Nuestro Señor de Esquipulas fue entronizada en el templo por el obispo José Flore de Rivera. Dicho templo es el único edificio colonial que queda en el departamento de Managua.

Dentro del paisaje natural, se destaca el río Tipitapa que mide $35 \mathrm{~km}$ de largo. Este une al lago de Nicaragua con el lago Xolotlán y se encuentra aproximadamente a 10 metros más alto que el lago Cocibolca, por lo tanto, cuando el nivel del lago de Xolotlán se eleva, las aguas de éste corren por el río provocando inundaciones en la parte norte de la ciudad.

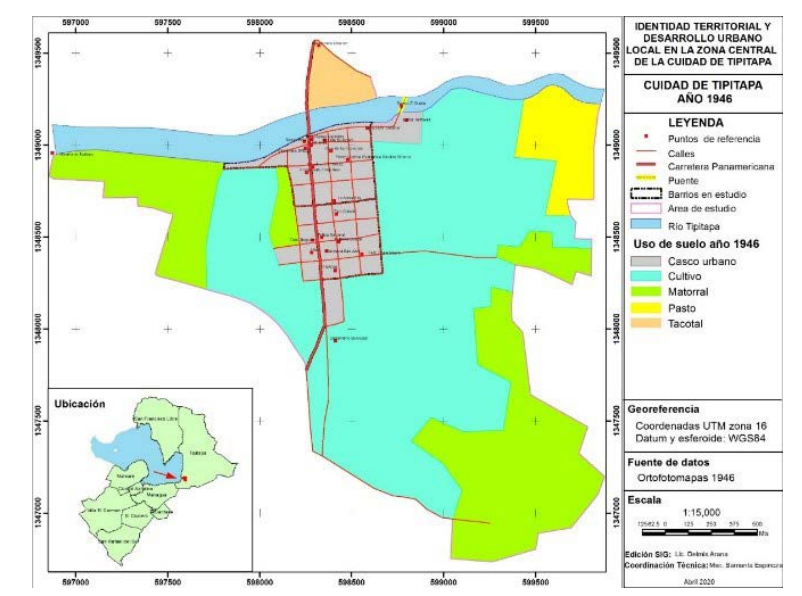

Figura 1. Mapa de la zona central de la ciudad de Tipitapa en el año 1946 


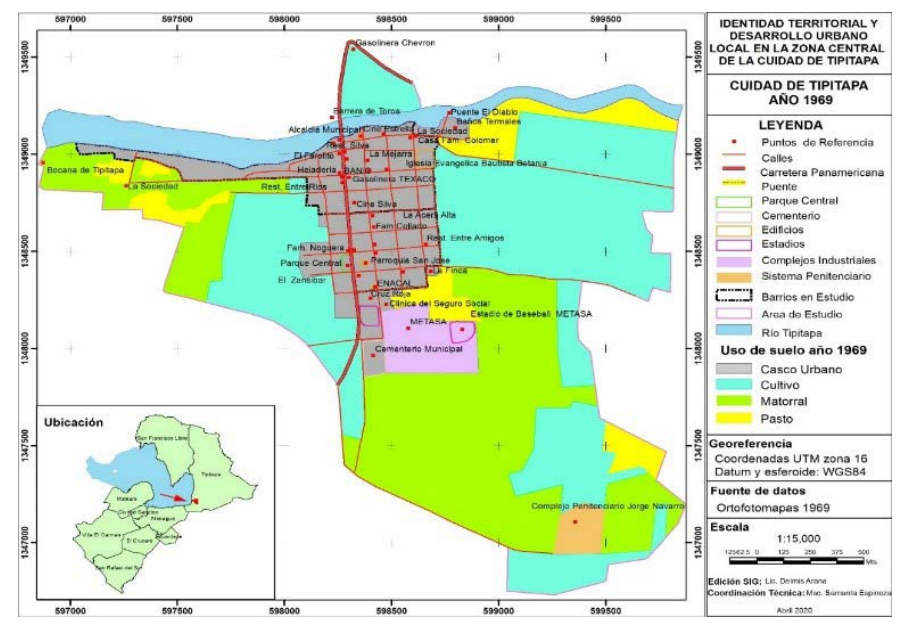

Figura 2. Mapa de la zona central de la ciudad de Tipitapa durante 1969

En síntesis, es importante destacar que en el primer periodo (1946 y 1969), la ciudad de Tipitapa fue llamada Villa Stimpson (elevada a villa en 1929). No existía información suficiente y tampoco existía un plan regulador del desarrollo urbano, por lo tanto, la municipalidad brindó solución según aparecían las problemáticas. Con respecto al uso del suelo, el uso más sobresaliente fue cultivos, matorral y pasto, donde sobresalen las haciendas ganaderas. En cuanto al uso de casco urbano (muy reducido en ese entonces), Tipitapa antes de 1970 estuvo conformada por los barrios La Bocana y Roberto Vargas. Su morfología fue de estilo colonial. Con respecto a la vialidad, presenta una primera subdivisión de calles (calles principales y secundarias).

También, se logró constatar que los factores geográficos relevantes para el desarrollo urbano en el periodo (1946-1969) fueron los siguientes: en primera instancia se ubica en un tramo de la carretera Panamericana y su relieve, porque la ciudad de Tipitapa se asienta en la zona costera sur oriental del Lago Xolotlán (Managua), con alturas de 37 hasta 68 m.s.n.m. Por el extremo Norte de la ciudad pasa el río Tipitapa que une los Lagos Xolotlán y Cocibolca. En segundo lugar, las actividades productivas (agricultura y ganadería), donde se destacan grandes haciendas agropecuarias, la ubicación de industrias, así como hechos históricos que marcaron el suelo citadino de historia nacional. Lo anterior contribuyo a que Tipitapa empiece a funcionar como una ciudad enlace.

\section{b) Segundo período: 1996 y 2000}

\section{Uso de suelo}

Según los ortofotomapas de los años 1996 y 2000, la cobertura de suelo que sobresale tanto en los mapas de 1996 y 2000 es casco urbano (205 ha), seguida de cultivos (109 ha) y de pastos (52 ha) (figura 3 y 4,). Esta experimentó un aumento debido al crecimiento demográfico (de 47,779 habitantes en 1995 a 91.632 en el año 2000, según estimaciones del Instituto 
Nicaragüense de Estadísticas y Censos). Las tres coberturas (casco urbano, cultivos y pasto) se mantuvieron con respecto al año 2000, mientras que las coberturas de matorral y pasto disminuyeron por completo. La disminución de las áreas de los cultivos, se produjo a que en los primeros años de la década de los años 90 se dio un descenso en el aprovechamiento de la tierra de la jurisdicción de Tipitapa y por ende en los niveles productivos.

Como se mencionó en párrafos anteriores, el tejido urbano de Tipitapa continúo incrementando y se mantuvo en los años 1996 y 2000; específicamente en el centro del casco urbano y áreas periféricas conectadas de este a oeste, consistentes en grandes bloques de viviendas junto a las vías principales y nuevos centros industriales. Durante estos años, se expandió su trama urbana y nuevos barrios aparecen. En este sentido, el mapa de 1996 presenta los barrios que surgieron de la Revolución Popular Sandinista, tales como: Teófilo Rivas, Juan Castro, Pedro Joaquín 1, Pedro Joaquín 2, Omar Torrijo, Ana Virginia Robles, México, Rubén Ulloa, Villa Victoria de Julio, Anexo Villa Victoria de Julio, Antonio Mendoza y Colonia Marco Somarriba.

El mapa del año 2000 muestra nuevos barrios, tales como: Lomas de Esquipulas, que se creó para ubicar a las familias damnificadas por el paso del huracán Mitch ocurrido en octubre de 1998, Colonia Los Maestros y El Chaparral (Figura 4).

\section{Morfología urbana}

La ciudad de Tipitapa sufrió muchos más cambios que en los años anteriores, ya que se terminan de ocupar los espacios entre los barrios mencionados anteriormente y surgen nuevos barrios. En cuanto al contorno de la ciudad, este se vuelve completamente irregular como se puede apreciar en las figuras 3 y 4 . La traza se adapta a la forma del terreno en algunas ocasiones y en otras se utilizan como referencias pequeños caminos de tierra que ya existían en la zona. La forma de las manzanas, específicamente en el centro se observan cuadradas con ciertas irregularidades, en los barrios ubicados al este, sur y oeste se aprecian manzanas rectangulares de varios tamaños con forma irregular.

\section{Infraestructura vial y accesibilidad}

Debido a que Tipitapa aún no posee un reglamento vial, las vías no tienen una nomenclatura específica, pero sin embargo se puede clasificar según su importancia, volumen de tránsito y dimensiones en cuatro tipologías:

- Vía colectoras primarias, representadas por la Carretera Panamericana que une a Tipitapa con la ciudad de Managua, por el sur, y por el norte con las regiones del norte, centro, caribe y oriente del país.

- Vías colectoras secundarias, referidas a las que sirven de comunicación con las comarcas del municipio de Tipitapa, como por ejemplo el camino 
que va hacia San Juan La Playwood.

- Sistema de calles, que se proyectan de este a oeste, de norte a sur, teniendo como calle principal la que nace en la ribera sur del río Tipitapa (sector Aguas Caliente) y se prolonga hacia el sur (empalme de Tipitapa). Esta calle principal aparece como la vía Panamericana en el periodo anterior.

La ciudad de Tipitapa posee una red que le permitió la interconexión y comunicación tanto a nivel internacional, nacional como a lo interno del municipio y su área urbana. Dentro de esta red de vías se encuentran las carreteras catalogadas como vía troncal y red de calles. La vía troncal principal la constituye la carretera Panamericana, ubicada en el sector oeste y sur de la ciudad. Esta carretera pavimentada le garantiza a la ciudad su conexión con el resto del país y países de la región centroamericana. A lo interno de la ciudad, Tipitapa cuenta con una red de calles adoquinadas que permiten la conexión entre los distintos barrios que conforman el casco urbano.

De 1996 al 2000, el río Tipitapa experimentó una crecida más en 1998, donde la carretera Panamericana quedó cortada. La bocana del río se amplió debido al huracán Mitch. Este tuvo crecidas en los años 1927, 1933 y 1956 según registros del Instituto Nicaragüense de Estudios Territoriales (INETER). Después del huracán Mitch fue necesario la construcción de un puente en la carretera Panamericana para reanudar el tráfico vehicular, también se construyó un puente provisional llamado Mitch en el sector de Lomas de Esquipulas.

\section{Actividades productivas}

El distrito 8 de la Policía Nacional fue fundado por el Ministerio del Interior y la Policía Sandinista (hoy llamada Policía Nacional) en 1979. Este se localiza donde estuvo el comando de la Guardia Nacional, en el costado norte del templo San José. Por otro lado, se destaca la fábrica Metales y Estructuras, S.A. (METASA) que se fundó en 1964 y, en 1999 cambia de nombre a Inversiones y Negocios de Nicaragua, S.A. (INDENICSA). Esta produce y comercializa productos metalúrgicos derivados del acero. También se dedica a la línea de productos de concreto. Cuenta con dos plantas de producción, ubicadas en Tipitapa y Cofradía. Por otra parte, se destaca el Mercado Municipal Danilo Medina que es el principal centro de comercio y abastecimiento de la ciudad de Tipitapa. Tiene un área de 2,900 metros cuadrados, distribuidos tanto en el interior como en el exterior, cubriendo las aceras en sus cuatro costados. Tiene cobertura municipal.

En cuanto a los lugares de recreación, se destaca Los Baños Termales, lugar donde se localizan fuentes de aguas termales, que fueron atracción de curiosidad de españoles, indígenas, gringos y visitantes, que son atraídos por las propiedades medicinales de sus aguas y para diversión. El Parque Central que se localiza en el mismo lugar de los años anteriores (frente a la parroquia San José), ha sido varias veces renovado con juegos para niños, 
bancas, casetas, cancha de basquetbol y fútbol, entre otros. Así mismo, sobresale el cine Silva, ubicados en la calle central, frente del mercado y, el cine Estrella en el sector noreste del casco urbano.

El Cine Silva está ubicado al frente del mercado municipal Danilo Medina, este cine se construyó como el principal dispositivo cultural para los pobladores de Tipitapa. Surgió el 15 de mayo de 1982, como empresa familiar. Tenía como objetivo principal promover la recreación de los habitantes de Tipitapa. Sus fundadores fueron: Celinda Silva, Denis Silva, Leonel Silva y Norma Silva. El auge de este cine se dio entre 1982 y 1997. La entrada costaba cinco córdobas.

Según la entrevista doña Celinda Silva, el cine Silva tenía capacidad para doscientas y trescientas butacas; el edificio tenía dos plantas: baja y alta. Diariamente asistían al cine alrededor de ochenta o cien personas quienes solían disfrutar de las películas de largometraje. También, se refirió que los días que más se llenaban era cuando se presentaban películas "prohibidas" (El Nuevo Diario, 2020).

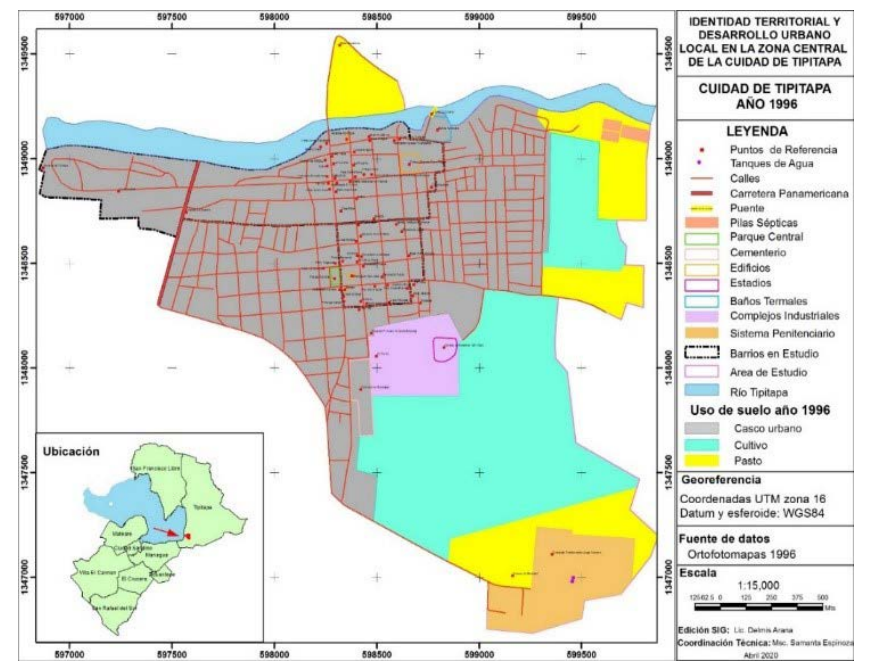

Figura 3. Mapa de la zona central de la ciudad de Tipitapa en el año 1996

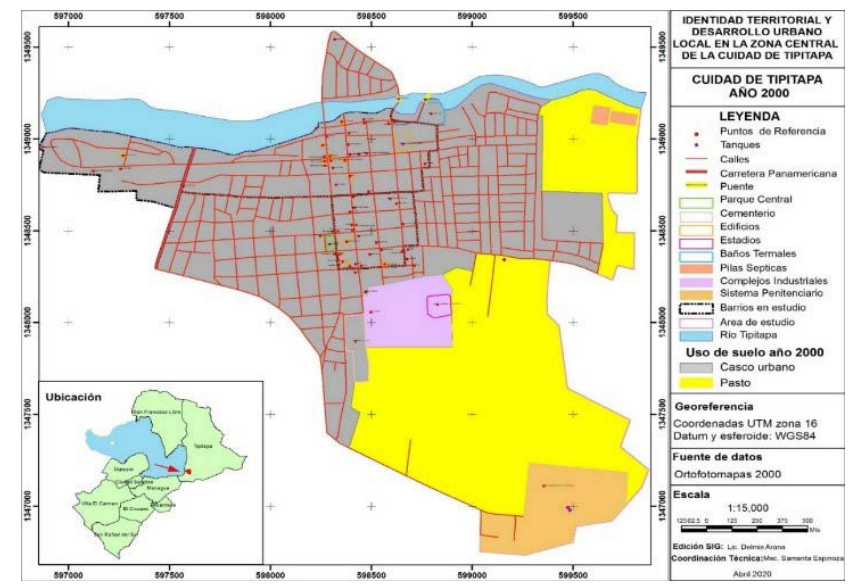

Figura 4. Mapa de la zona central de Tipitapa en el año 2000 
La ciudad de Tipitapa cuenta con el cementerio municipal en los años 1996 y 2000. Se ubica hacia el sur del casco urbano, contiguo a INDENICSA. En cuanto al complejo penitenciario Jorge Navarro, continúa en el sector sureste de la ciudad. Forma parte de la red de penitenciario nacional. Por otro lado, en este periodo continuó destacándose el templo San José de Tipitapa, ubicado en la calle central del casco urbano, frente al parque. Además, de iglesias de denominación evangélica. En el mapa de 1996, la ciudad de Tipitapa cuenta con el Hospital Primario Yolanda Mayorga, que funciona desde 1960. Se ubica para este periodo, contiguo a Metales y Estructuras, S.A. (METASA). Fue remodelado en 1985 sobre los mismos cimientos, sin haberse renovado su infraestructura hidrosanitaria y eléctrica. Para este periodo, el hospital se encuentra en condiciones precarias.

En resumen, los principales factores que influyeron en el desarrollo de la ciudad fueron los hechos previos a los años 90, como el terremoto de 1972 (una de las causas del crecimiento de la ciudad), la Revolución Popular Sandinista (1979), el incremento de zonas industriales y la inmigración. Al respecto, el poblador Castro Sánchez mencionó en la entrevista realizada por el periodista Mario Tapia (2018) que:

Hoy la población de Tipitapa es originaria de toda Nicaragua; de San Pedro de Lovago, Camoapa, Santa Lucia, Jinotega, Ocotal, Somoto, Estelí, León, Tola, Granada, Masaya, Chinandega y Boaco. De Tipitapa, entre las 4, 5, 6 y 7 de la mañana salen centenares de buses con gente hacia Managua, Masaya, Estelí, Boaco, Chontales, Matagalpa donde va a laborar, y diario, a las 5 de la tarde, está volviendo, solo vienen a dormir. Por eso es que nosotros la llamamos una ciudad dormitorio (pág. 6).

\section{c) Tercer periodo: 2018 y 2020}

\section{Uso de suelo}

Para los años 2018 y 2020, la zona central de la ciudad de Tipitapa registra el mayor crecimiento de la cobertura de casco urbano, este pasó de 205 ha en el año 2000 a 294 ha en el 2018. El incremento se debe al aumento de la población en términos absolutos en comparación con cualquiera de los otros periodos observados. En cuanto a la cobertura de uso de cultivos, matorral y tacotal continuaron con su regresión: el abandono de áreas de cultivos se consume casi en su totalidad, mientras que la cobertura del casco urbano asciende (figura 5). Este creció en dirección sur y este.

\section{Morfología urbana}

La zona central de la ciudad para el año 2018 experimentó más cambios que el periodo anterior, ya que se finalizan la ocupación de los espacios entre los barrios anteriores y surgen nuevos barrios como El Barrio Nuevo, ubicado en la zona este del casco urbano. Por otra parte, el contorno de la ciudad se vuelve completamente irregular (Figura 5). La traza se adapta a la forma 
del terreno en algunas ocasiones y en otras se utilizan como referencias pequeños caminos de tierra que ya existían en la zona. La forma de las manzanas, específicamente en el centro histórico se observan cuadradas con ciertas irregularidades. En los barrios ubicados al este, sur y oeste se aprecian manzanas rectangulares de varios tamaños con forma irregular.

\section{Infraestructura vial y accesibilidad}

En cuanto a la vialidad, la ciudad de Tipitapa presenta tres tipos de vías: interregional, intermunicipal e Inter comerciales clasificadas de acuerdo a su importancia en el municipio y al flujo vehicular que circula en ella.

La carretera interregional corresponde al tramo de la carretera panamericana que atraviesa el municipio de norte a sur, tiene una longitud de $48 \mathrm{Km}$. Este corredor posee el flujo vehicular más importante del municipio, ya que es una vía internacional, en el que circulan vehículos provenientes de los países del sur y norte de Centroamérica, la región central del país y la zona caribeña nicaragüense. Condición que fomenta la importancia del municipio, ya que lo convierte en un importante puerto de comunicación terrestre y un centro de articulación e interacción comercial.

La carretera intermunicipal, representada por tres tramos: El primero comienza desde empalme San Benito hacia la carretera a Ciudad Rama. El segundo tramo comprende desde la garita (salida norte de Managua hasta el empalme de Masaya); conocida como carretera vieja a Tipitapa, su importancia radica en establecer la línea de comunicación directa entre la cabecera y municipal Managua, representa la principal ruta de transporte interurbano entre ambas ciudades. Este tramo de carretera es de gran importancia, por la presencia de las principales industrias y por ubicarse dentro de la zona con potencial agrícola.

El tercer tramo de la carretera intermunicipal inicia en el empalme de Masaya hasta la comunidad Los Trejos. Esta se considera de importancia porque circula toda la producción proveniente del norte y centro del país hacia los departamentos de Masaya, Granada y Rivas; con el fin de evitar el congestionamiento vial de la ciudad capital.

Las carreteras intercomarcales: Conforman el tercer nivel jerárquico; correspondiente a los caminos que comunican a las diferentes comarcas. Como se aprecia en la figura 5, Tipitapa es atravesado de extremo a extremo por la carretera Panamericana, que es la vía más importante del país, en la que circula el transporte terrestre de mayor importancia de carácter nacional e internacional, de igual forma se observa en la parte sur las vías de penetración conformada por carreteras de todo tiempo. 


\section{Actividades productivas}

La ciudad de Tipitapa continúa fortaleciendo los sectores de industria y comercio. Estas se han desarrollado aceleradamente en los últimos 15 años. Se cuenta con más de 50 empresas. Parte de ellas se localizan en la zona central del casco urbano, tales como: Industria Metal Mecánica y comercio (mercado, tiendas, servicios, supermercado). La ciudad a diferencia de otras cabeceras municipales, presenta una actividad industrial considerable, la cual se ha desarrollado debido a algunos factores que han influido grandemente en el establecimiento de industrias manufactureras entre los cuales están: su cercanía con Managua, los incentivos fiscales, la mano de obra de bajo costo, los costos de producción más baratos y su ubicación geográfica estratégica, con relación al norte y pacifico del país.

La actividad comercial del municipio se concentra en la cabecera municipal, y representa el $44.47 \%$ de las actividades que conforman este sector. Existen diversos establecimientos, representando el mayor porcentaje ( $88 \%$ del total) las pulperías y ventas menores, seguido de forma equitativa, por tiendas de mercadería en general, ferreterías, ventas de frutas, expendios de licor, ventas de granos, carnicerías, ventas de lubricantes, panaderías y en menor grado funerarias, ventas de repuestos y comercializadoras de café.

En el mapa de 2018 aparece el Hospital Primario Yolanda Mayorga con nueva infraestructura. Este se ubica en el sector extremo norte de la ciudad de Tipitapa. También, se localiza la estación del Benemérito Cuerpo de Bomberos y oficinas de entidad pública.

Por otro lado, la ciudad de Tipitapa cuenta con centros de interés cultural como la iglesia San José que es la más antigua del departamento de Managua y, es famoso por la veneración al santo patrono Nuestro Señor de Esquipulas o Cristo Negro que, por tradición se celebra todos en el mes de enero con desfiles hípicos, coronación de la reina patronal, carreras de cinta, tope y corridas de toros. También se destacan las casas antiguas que evidencian la forma de vida de los habitantes que poblaron la ciudad de Tipitapa en sus inicios. De igual manera, la ciudad de Tipitapa continúa albergando la tradición culinaria del pescado sin espinas o a la Tipitapa. Asimismo, se destaca restaurante Entre Río, centro turístico de los baños termales. 


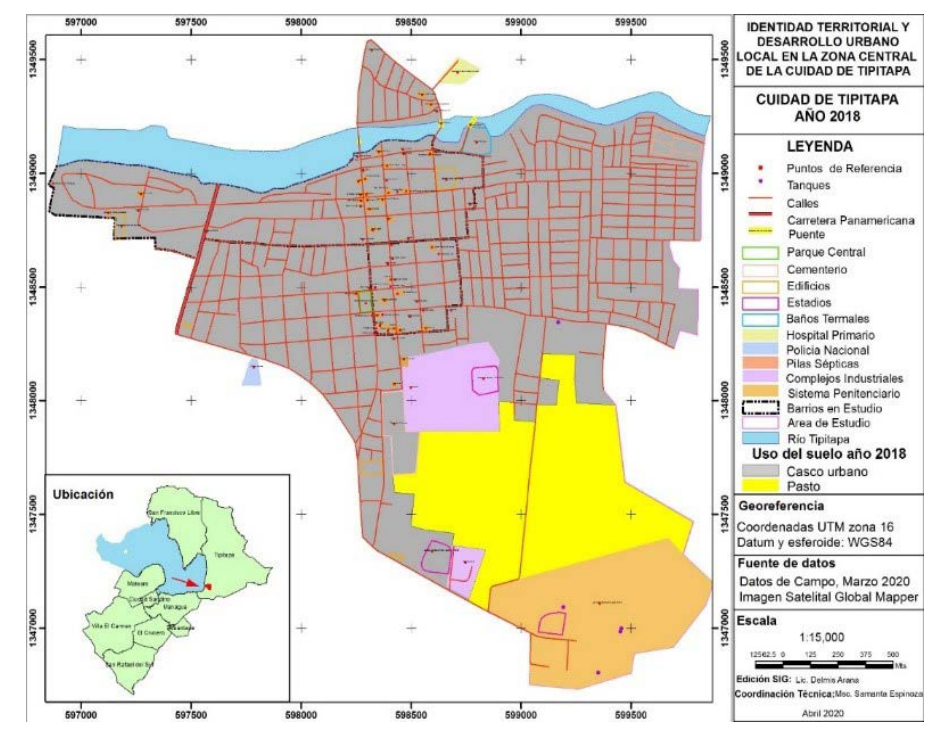

Figura 5. Mapa de la zona central de la ciudad de Tipitapa en el 2018

Dicho lo anterior, se encontró que el desarrollo urbano de Tipitapa en los años 2018 y 2020 ha estado influenciado por factores geográficos que coexisten y que han forjado la base de la identidad territorial, específicamente en los barrios Roberto Vargas y La Bocana que representa el centro histórico de la ciudad de Tipitapa. Dentro de los factores geográficos se encontraron los siguientes:

En primer lugar, se destaca el relieve y ubicación geográfica, esta última permite que funcione como una ciudad enlace. Durante la revisión documental, se encontró que el Plan Maestro de Desarrollo Urbano de Tipitapa (PMDU) 2004-2024 visualiza a la ciudad como "ciudad de enlace y ciudad turística", así se afirma cuando indica "se visualiza a la ciudad de Tipitapa jugando un rol de Ciudad Enlace (...) permitiendo la convergencia comercial y de servicios entre el Norte, Atlántico, Centro y Pacifico del país" (Alcaldía Municipal de Tipitapa, 2005). En segundo lugar, la viabilidad y accesibilidad a la ciudad de Tipitapa.

En este sentido, el PMDU indica que el casco urbano posee una ubicación privilegiada por su cercanía con la capital del país $(22 \mathrm{~km})$, facilita su territorio para el cruce (empalme) de importantes vías de comunicación de nivel nacional y regional, como la carretera Panamericana, que comunica a Nicaragua con los demás países centroamericanos y al Municipio de Tipitapa con las regiones norte y sur, centro y caribe nicaragüense.

Asimismo, Tipitapa se localiza dentro del eje Managua-Masaya-Granada, que constituye la región con mayor concentración poblacional de Nicaragua, sede de las actividades socio económicas de mayor relevancia. Se encontró que la visión del PMDU es compartida por los habitantes de la ciudad, cuando hicieron memoria en el grupo focal y entrevista semiestructurada, al manifestar que la ubicación geográfica de Tipitapa le agrega un sentido 
de importancia porque en ella se ha establecido desde tiempo pasado el comercio y ha jugado un papel fundamental por ser un puente comercial entre el norte y la ciudad de Managua.

Al respecto, citó a J. Sánchez, (comunicación personal, 04 de febrero de 2020) que señaló "La ciudad de Tipitapa tuvo mayor incidencia comercial que Managua. Toda la producción del norte del país pagaba impuesto para pasar hacia el sur del país. Existieron los mercados de calles con expresiones de vendedores heredadas por los españoles". Así mismo, (D. Cuaresma, comunicación personal, 04 de abril de 2020), expresó "Me gusta Tipitapa por su ubicación geográfica, ya que tenemos conexión con el norte, sur, centro y estamos cerca de la capital del país".

En tercer lugar, se encontró que el suelo en la zona de estudio se ha utilizado para cultivos, matorral, pasto, tacotal y casco urbano. Así mismo, se constató que los usos mencionados anteriormente se transformaron en su extensión territorial, donde el uso del casco urbano experimentó incremento de área de 46 ha en 1946 a 291 ha en el año 2018, esto se refleja en los elementos de la morfología urbana (contorno, traza y diseño de las manzanas), disminuyendo áreas de cultivos y demás usos como consecuencia del crecimiento demográfico y actividades industriales y comerciales.

Sumado a lo anterior, los elementos de la morfología urbana como el contorno, la traza y el diseño de las manzanas que hoy posee la ciudad no es la misma hace 74 años, en el tiempo y espacio. En este sentido, se encontró que la morfología de la ciudad ha estado influenciada por la localización (su cercanía a la capital de Nicaragua), lugar de cruce de principales vías de comunicación del país, destacándose la carretera Panamericana, las actividades productivas como la agricultura, ganadería, industria de manufactura y metalúrgica, así como el comercio.

Lo anterior, se fundamenta cuando se señala que la ciudad moderna se desarrolla en torno al mercado y constituye el centro de una región de producción altamente especializada, con su correspondiente área comercial muy extensa. En estas circunstancias, el perfil de la ciudad moderna está determinado por la geografía local y las rutas de transporte (Ezra Park, 1999). Asimismo, se basa en una relación íntima entre el desarrollo del capitalismo y el proceso de urbanización. También, indica que no es sorpresa que el crecimiento del producto capitalista con el tiempo sea prácticamente idéntico a la de la urbanización de la población mundial (Harvey, 2013).

Por consiguiente, la ciudad de Tipitapa ha experimentado un crecimiento que, en cierta medida responde a la dinámica capitalista, en cuanto se refiere a la evolución de las ciudades en el tiempo y espacio. En cuarto lugar, las migraciones hacia el municipio de Tipitapa han estado marcado por dos tipos de condicionantes: las acciones de impacto en el desarrollo de fuentes de trabajo y desastres de origen natural. También, es importante destacar que 
la cultura urbana de la ciudad de las ciudades sufren profundas y aceleradas transformaciones, producto de factores concernientes al crecimiento de la población, al aumento de la inseguridad ciudadana y, a la falta de políticas urbanas (Álvarez Arzate, 2000).

La ciudad es el espacio donde se desarrollan complejas relaciones sociales, culturales, políticas y económicas, de personas con diferentes procedencias geográficas, diversas concepciones acerca de sí mismo, de los otros, de intereses y motivaciones de vida muy diferentes (Álvarez Arzate, 2000). En este sentido, la zona central histórica de la ciudad de Tipitapa ha experimentado transformaciones en los distintos años, producida por factores geográficos relacionados con su ubicación geográfica, el crecimiento de la población, causado principalmente por la inmigración. Lo anterior, se logró registrar en los mapas-modelo de la evolución urbana.

Por otro lado, es importante hacer referencia a la memoria colectiva que es definida en el tiempo y espacio, es decir en la existencia de unos marcos temporales que logran situar los recuerdos. La memoria colectiva se apoya en imágenes espaciales. No hay memoria colectiva que no se desarrolle en un marco espacial. Los objetos con los cuales estamos en contacto cotidianamente nos dan una imagen de permanencia y de estabilidad (Halbwachs, 2004). En este sentido, "Cada localización es, pues, un momento del inmenso movimiento del mundo, (...) gracias al movimiento social, cada lugar está siempre cambiando de significado: en cada instante las fracciones de la sociedad que incorpora no son las mismas" (Santos, 2009, pág. 148).

La Topofilia se considera como el lazo afectivo entre las personas y el lugar o el ambiente circundante. En este sentido, los habitantes de la zona central histórica de la ciudad de Tipitapa manifestaron un lazo afectivo entre las personas y el lugar $o$ el ambiente circundante, donde los significados edificados en esta relación son los que demuestran esos "lazos intangibles" que atribuyen de humanidad los espacios (Tuan, 2007). Los habitantes insistieron en manifestar que se identifican con las tradiciones culturales y los lugares de su ciudad, tales como: Iglesia San José de Tipitapa, lugar donde se venera la imagen del Señor de Esquipulas, patrono del Municipio de Tipitapa. De igual manera, el Pacto del Espino Negro, el "Puente del Diablo". En cuarto lugar, otro factor geográfico dinamizador en la evolución urbana del área central histórica de Tipitapa ha sido la migración. Al respecto, el poblador Castro Sánchez que mencionó:

Hoy la población de Tipitapa es originaria de toda Nicaragua; de San Pedro de Lovago, Camoapa, Santa Lucia, Jinotega, Ocotal, Somoto, Estelí, León, Tola, Granada, Masaya, Chinandega y Boaco. De Tipitapa, entre las 4, 5, 6 y 7 de la mañana salen centenares de buses con gente hacia Managua, Masaya, Estelí, Boaco, Chontales, Matagalpa donde va a laborar, y diario, a las 5 de la tarde, está volviendo, solo vienen a dormir. Por eso es que nosotros la llamamos una ciudad dormitorio (Tapia, 2018). 


\section{CONCLUSIONES}

En conclusión, la ciudad de Tipitapa ha presentado un crecimiento variado a través de los años. A partir de la década de los años sesenta, la población aumentó, siendo las actividades agrícolas y comerciales, factores que incentivaron la migración de pobladores de pueblos vecinos como Granada, Masaya, Managua, de la zona norte y caribe del país.

Para los años sesenta, la ciudad presentó un crecimiento en relación a los años anteriores, la población se incrementó por los movimientos migratorios ocasionados principalmente por factores sociales, económicos y desastres de origen natural, que afecto la capital Managua, mientras esta ciudad pasaba por el proceso de reconstrucción, sus habitantes emigraron hacia la ciudad de Tipitapa y a otros pueblos vecinos.

En los años ochenta, la población de la ciudad de Tipitapa llega a duplicarse, debido a la situación de guerra que vive Nicaragua. Los pobladores del norte emigran hacia el Pacifico y por lo tanto a Tipitapa en busca de medios de vida, donde el auge del cultivo de caña de azúcar representa un atractivo para asentarse en esta. Por otro lado, en los años noventa y dos mil, Nicaragua se encuentra en un proceso de pacificación que permitió la estabilidad en la forma de vida de los pobladores, donde se crearon condiciones económicas y sociales para iniciar la reconstrucción del país.

A lo anterior, se sumó los nuevos asentamientos humanos como producto del paso del huracán Mitch en 1998. Es importante enfatizar, que uno de los elementos importantes en el crecimiento de la ciudad, fue la migración del campo a la ciudad, debido a su cercanía con la capital de Nicaragua y las zonas francas industriales. Asimismo, la migración, donde se destacan acontecimientos detonantes de esta, como la Revolución Popular Sandinista, ya que a partir de ella se crearon nuevos barrios, la instalación de energía eléctrica en la zona urbana y la red de acueductos y alcantarillados. También se destaca los desastres de origen natural como el huracán Mitch, el terremoto de la ciudad de Managua en 1972. Esto provocó la aparición de nuevos barrios, que fueron tomando forma según las características del terreno.

Los factores geográficos antes mencionados han contribuido al desarrollo urbano de Tipitapa, propiciando condiciones de productividad de las actividades económicas que permiten la producción social, por otra parte, a la competitividad. Esto aumenta a futuro la posibilidad de inversiones en la ciudad de Tipitapa. El desarrollo urbano ha estado influenciado por las vías de comunicación, que según el plan maestro de desarrollo urbano de Tipitapa (2004-2024), Tipitapa es una ciudad tiene potencialidades en el orden físico natural, que permite proyectar el desarrollo de una ciudad que cumpla con un rol de enlace de servicios a nivel nacional. Es una ciudad con 
altos niveles de accesibilidad haca el interior como a los centros urbanos por las vías de interconexión que atraviesan la ciudad.

El futuro de la ciudad de Tipitapa puede visualizarse en varios escenarios posibles, donde los factores demográficos, económico y social, así como político-administrativos son condicionantes. En este sentido, la migración será un factor que siga influyendo en crecimiento y desarrollo de la ciudad, así como las fuentes de empleo.

Dicho lo anterior, se recomienda los diagnósticos territoriales para la actualización de información y creación de observatorio urbano que permitan desarrollar escenarios urbanos para incorporarlas en las estrategias de desarrollo de la ciudad de Tipitapa.

\section{REFERENCIAS BIBLIOGRÁFICAS}

Acuña Vigil, P. (2005). Análisis formal del espacio urbano. Aspectos teóricos. Análisis formal del espacio urbano. Aspectos teóricos. Lima, Lima, Perú.

Alcaldía Municipal de Tipitapa. (2005). Plan Maestro de Desarrollo Urbano Ciudad de Tipitapa 2004-2024. Alcaldia Municipal de Tipitapa, Managua, Tipitapa.

Álvarez Arzate, M. (7 de Abril de 2000). La ciudad ausente, políticas urbanas y espacios de socialización. Managua, Managua, Nicaragua. Obtenido de https://antropologia-nica.blogspot.com/2007/04/la-ciudad-ausentepolticas-urbanas-y.html

Augé, M. (1992). Los no lugares: Espacios del anonimato. Barcelona: Gedisa, S.A.

Barreto, P. (2002). Tipitapa. Suelo cubierto de historia nacional. Managua, Nicaragua: Impresos Monseñor Lezcano.

Belli, P. (1975). Prolegomeno para una historia económica de Nicaragua 1905-1966. Revista del pensamiento centroámericano, 13-16.

Boiser, S. (1996). Modernidad y Territorio. Santiago, Chile: Cuaderno de ILPES.

Boiser, S. (2003). El desarrollo en su lugar: El Territorio en la sociedad del conociemiento. Chile, Chile: Serie GeoLibros, PUC.

Bosque, J., \& C. García, R. (2000). El uso de los sistemas de información geográfica en la planificación territorial. Anales de Geografía de la Universidad Complutense, 49.

Doval, A. (2004). Nuevas realidades territoriales para el siglo XXI desarrollo local, identidad territorial y ciudad difusa. Madrid, España: Editorial Síntesis.

Ezra Park, R. (1999). La ciudad y otros ensayos de ecología urbana. Barcelona, España: Arts Grilfiques Hurope, S.L. 
Gallicchio, E. (7 de octubre de 2020). FLACSO Ecuador. Obtenido de FLACSO Ecuador: https://flacso.edu.ec/cite/media/2016/02/Gallicchio-E_2004_ El-desarrollo-local-en-America-Latina.-Estrategia-politica-basada-en-laconstruccion-de-capital-social.pdf

Gómez Romero, C. (2014). La Fundamentos epistemológicos de los estudios urbanos estructuralista. Documentos de trabajo. Asunción, Asunción, Paraguay.

Halbwachs, M. (2004). La memoria colectiva. Zaragoza, España: Prensas universitarias de Zaragoza.

Halftermeyer, G. (1946). Managua a través de la Historia 1846 - 1946. León: Hospicio San Juan de Dios.

Harvey, D. (2013). Ciudades rebeldes. Del derecho de la ciudad a la revolución urbana. Madrid, España: Ediciones Aka!, S. A.

Ingram Alfaro, S. M., \& Esteban Moreira, J. d. (noviembre de 2013). Analisis de la evolución urbana de la ciudad de Jinotepe entre los años 18832012. Monografía para obtener el titulo de arquitecta. Managua, Managua, Nicaragua.

MappingGIS. (24 de septiembre de 2021). MappingGIS. Obtenido de MappingGIS: https://mappinggis.com/2014/07/como-georreferenciaruna-imagen-con-arcgis/

Mazurek, H. (2009). IRD Editions. Obtenido de IRD Editions: https://books. openedition.org/irdeditions/17840? lang=es\#text

Moraga López, G. (2010). Geografía cultural e identidad territorial: el caso de la comunidad de Cabuya, distrito de Cóbano, Puntarenas, 2009. Revista Geográfica de América Central, 131-154. Recuperado el 02 de enero de 2019, de https://www.revistas.una.ac.cr/index.php/geografica/ article/view/3295

Ramírez Velázquez, B. R., \& López Levi, L. (2015). Espacio, paisaje, región, territorio y lugar: la diversidad en el pensamiento contemporáneo. Mexico, D.F, México: Universidad Nacional Autónoma de México.

Rozas, G. (1997). Identidad y desarrollo regional. Revista de Psicología de la Universidad de Chile, 70.

Santos, M. (2009). Espacio y método: Algunas reflexiones sobre el concepto de espacio. Gestión y Ambiente, 148.

Tapia, M. (19 de agosto de 2018). Gente de Gallos. Obtenido de Gente de Gallos: http://www.gentedegallos.com.ni/culturales/historia/historia-detipitapa/

Tuan, Y. (2007). Topofilia. Un estudio de las percepciones, actitudes y valores sobre el entorno. Madrid, España: Editorial Melusina. 